\title{
Management of eye emergencies in the accident and emergency department by senior house officers: a national survey
}

\author{
M M S Tan, P A Driscoll, J E Marsden
}

\begin{abstract}
Objective-To assess the training that accident and emergency (A\&E) senior house officers (SHOs) receive in dealing with eye emergencies, their own perceived level of confidence and competence in managing such cases, and the availability of appropriate equipment in their departments.

Methods-Prospective telephone survey using a standardised structured questionnaire. One SHO from each United Kingdom A\&E department listed in the BAEM directory of 1993 was chosen at random and interviewed.

Results-226 A\&E departments were contacted and 192 SHOs were successfully interviewed (response rate $84.9 \%$ ); $26.0 \%$ received no training in the management of eye emergencies, $68.8 \%$ had only a little or no confidence in dealing with these cases, and $42.2 \%$ worked in $A \& E$ departments which had no slit lamp.

Conclusions-There is a lack of adequate basic ophthalmic training for A\&E SHOs, leading to a lack of confidence on their part in the management of eye emergencies. In just over $40 \%$ of A\&E departments in the United Kingdom, the management of these cases may be less than optimal because of the absence of a slit lamp. (F Accid Emerg Med 1997;14:157-158)
\end{abstract}

Keywords: eye; emergencies; training

Eye emergencies constitute an important part of the workload in the accident and emergency (A\&E) department, comprising about $6 \%$ of all new attendances. ${ }^{1}$ Most of these conditions are minor and can be treated by doctors without extensive specialist training in ophthalmology. ${ }^{1}$ However, these doctors need basic ophthalmic training and knowledge, and the ability to use essential equipment such as the slit lamp. If these prerequisites are met, then most of these patients can be managed by the $A \& E$ department alone without the risk of serious eye pathology being overlooked. ${ }^{1}$

Most patients with eye complaints who present to the A\&E department are likely to be seen by a senior house officer (SHO) alone. ${ }^{2}$ It is therefore important to know how well qualified these junior doctors are in the management of eye emergencies.
Methods

A prospective telephone survey of all the $A \& E$ departments throughout the United Kingdom, as listed in the BAEM directory of 1993, was carried out. The survey was conducted during the months of September and October when all the SHOs had been in post for at least a month. In each department, an SHO was chosen at random and was asked over the telephone to provide answers to a series of questions from a set questionnaire. If the department was too busy at the time and no SHO was available for interview, it was contacted again a few days later. Some departments were contacted up to four times before an interview with an SHO was possible.

In seven $A \& E$ departments, patients who presented with an eye complaint were not seen by any medical staff but were asked to go directly to a nearby eye casualty department. These A\&E departments were excluded from the survey. Paediatric A\&E departments were also excluded.

\section{Results}

The full results of the survey are shown in the table, which gives details of the questionnaire used and the responses obtained. In summary, 226 A\&E departments were contacted and 192 SHOs were successfully interviewed (response rate $84.9 \%) ; 26.0 \%$ received no training in the management of eye emergencies, $68.8 \%$ had only a little or no confidence in dealing with these cases, and $42.2 \%$ worked in $\mathrm{A} \& \mathrm{E}$ departments which had no slit lamp.

\section{Discussion}

There has been a debate as to whether eye emergencies should be seen in a general $A \& E$ department or an eye casualty department. Ophthalmology SHOs would appear to offer better eye care than A\&E SHOs. ${ }^{3}$ However, it should be noted that:

(1) The deficiencies of A\&E SHOs in their management of eye cases as compared with ophthalmology SHOs relate mainly to assessment and examination omissions of a simple nature, which could be easily rectified. ${ }^{3}$

(2) There are only a few eye casualty departments which offer 24 hour open access to the public. This fact is borne out by this survey which showed that only seven A\&E SHOs nationwide stated that they did not see any eye emergencies but referred them directly to the eye casualty department. 
Table 1 Questions and responses

\begin{tabular}{|c|c|c|}
\hline Question & No of responses & Percentage \\
\hline \multicolumn{3}{|c|}{$\begin{array}{l}\text { 1. Have you had formal training and instruction in the management of eye emergencies in the A\&E } \\
\text { department? }\end{array}$} \\
\hline a. None & 50 & 26.0 \\
\hline b. Some & 106 & 55.2 \\
\hline c. Enough for my needs & 36 & 18.8 \\
\hline \multicolumn{3}{|c|}{ 2. If your answer to question 1 was (b) or (c), who taught you? (you may give more than one answer) } \\
\hline a. Senior A\&E medical staff & 98 & 69.0 \\
\hline b. Ophthalmic nurse practitioner & 9 & 6.3 \\
\hline c. Ophthalmic medical staff & 63 & 44.4 \\
\hline \multicolumn{3}{|l|}{ 3. Is there a slit lamp that you can use? } \\
\hline a. No access to one at all & 74 & 38.5 \\
\hline b. Access to one outside the $A \& E$ department & 7 & 3.6 \\
\hline c. Within the A\&E department itself & 111 & 57.8 \\
\hline \multicolumn{3}{|l|}{ 4. Have you ever been taught to use the slit lamp? } \\
\hline a. No & 101 & 52.6 \\
\hline b. Yes & 91 & 47.4 \\
\hline \multicolumn{3}{|l|}{ 5. How confident do you feel in the use of the slit lamp? } \\
\hline a. Not confident & 86 & 44.8 \\
\hline b. A little confident & 53 & 27.6 \\
\hline c. Confident enough & 53 & 27.6 \\
\hline \multicolumn{3}{|c|}{ 6. How easy or difficult is it for you to refer patients for specialist opinion and management? } \\
\hline a. Difficult & 7 & 3.6 \\
\hline b. Relatively easy & 68 & 35.4 \\
\hline c. No problem at all & 117 & 60.9 \\
\hline \multicolumn{3}{|l|}{ 7. If your answer to question 6 was (a), what was the reason? } \\
\hline a. There was no eye department nearby & 3 & 42.9 \\
\hline b. The eye department was often reluctant to accept your referral & 4 & 57.1 \\
\hline \multirow{2}{*}{ c. The patient could not be seen as quickly as you had hoped } & & 28.6 \\
\hline \multirow{2}{*}{\multicolumn{3}{|c|}{ 8. On an average working day, how many eye cases do you see? }} \\
\hline & & \\
\hline a. 1 or 2 & 77 & 40.1 \\
\hline b. 3-5 & 97 & 50.5 \\
\hline c. More than 5 & 18 & 9.4 \\
\hline \multicolumn{3}{|c|}{ 9. How confident are you in the management of eye emergencies in the A\&E department? } \\
\hline a. Not confident & 7 & 3.6 \\
\hline b. A little confident & 125 & 65.1 \\
\hline c. Confident & 60 & 31.3 \\
\hline \multicolumn{3}{|c|}{ 10. If your answer to question 9 was (a) or (b), what is the reason? (you may give more than one answer) } \\
\hline a. Not confident about the diagnosis and management & 71 & 53.8 \\
\hline b. Afraid that you may miss something important & 112 & 84.8 \\
\hline c. Not sure about what you should refer to the eye department & 43 & 32.6 \\
\hline \multicolumn{3}{|c|}{$\begin{array}{l}\text { 11. What would you like to see happen to give you greater confidence in the management of eye patients? } \\
\text { (you may give more than one answer) }\end{array}$} \\
\hline a. Formal training and teaching & 177 & 92.2 \\
\hline b. Better equipment in the $\mathrm{A} \& \mathrm{E}$ department & 63 & 32.8 \\
\hline c. Closer and better links with the Eye department & 98 & 51.0 \\
\hline a. and b. & 21 & 10.9 \\
\hline a. and c. & 50 & 26.0 \\
\hline$a, b$, and $c$. & 36 & 18.8 \\
\hline
\end{tabular}

The majority of patients with eye complaints who present to hospital are seen and treated, at least initially, by $A \& E$ SHOs rather than ophthalmology SHOs. The service for eye emergencies is therefore led by SHOs working in general $\mathrm{A} \& \mathrm{E}$ departments. ${ }^{2}$

Eye emergencies make up a diverse mix of cases, ${ }^{23}$ but the majority of them are due to minor trauma, resulting in abrasions or foreign bodies to the cornea or conjunctiva. ${ }^{13}$ The second commonest cause is inflammation/ infection. ${ }^{13}$ Most of these cases can be treated in a primary care setting, particularly if a slit lamp is available. ${ }^{45}$

There is no reason why A\&E SHOs, with the appropriate training and equipment, cannot manage these eye emergencies successfully, and at the same time recognise serious cases such as corneal ulcer, iritis, acute glaucoma, vitreous haemorrhage, and detached retina, which need urgent referral to the eye department. Specialist ophthalmic opinion and advice should be quickly available for such patients. The knowledge that such expert help is readily available will certainly increase the confidence of A\&E SHOs. In this survey, $84.8 \%$ of SHOs attributed their relative lack of confidence to the possibility that they may miss something important.
This survey has identified a definite need for more adequate training of $A \& E$ SHOs in the management of eye emergencies. It has also highlighted the fact that $42.2 \%$ of $A \& E$ departments will need to obtain a basic piece of equipment-a slit lamp-if such cases are to be managed appropriately. These changes are far easier to implement than to have all eye emergencies seen in eye casualty departments.

In the training of A\&E SHOs, ophthalmic medical staff should be involved as much as possible. This will contribute to a good working relationship between the two departments and also ensure more appropriate referrals.

1 Edwards RS. Ophthalmic emergencies in a district general hospital casualty department. $\mathrm{Br} \mathrm{J}$ Ophthalmol 1987;71:938-42.

2 Bhopal RS, Parkin DW, Gillie RF, Han KH. Pattern of ophthalmological accidents and emergencies presenting to hospitals. J Epidemiol Community Health 1993;47:382-7.

3 Flitcroft DI, Westcott $M$, Wormald R, Touquet R. Who should see eye casualties?: a comparison of eye care in an accident and emergency department with a dedicated eye casualty. J Accid Emerg Med 1995;12:23-7.

4 Levin AV. Eye emergencies: acute management in the pediatric ambulatory care setting. Pediatr Emerg Care 1991;7 367-77.

5 Janda AM. Ocular trauma. Triage and treatment. Postgrad Med 1991;90:51-2,55-60. 